\title{
Clinical evaluation of low cost Indian knee prosthesis in government medical colleges
}

\author{
Ansari Muqtadeer Abdul Aziz, Pratik Rathod*, Altamash Patel
}

Department of Orthopaedics, Government Medical College and Hospital, Aurangabad, Maharashtra, India

Received: 01 February 2021

Revised: 01 March 2021

Accepted: 03 March 2021

\author{
*Correspondence: \\ Dr. Pratik Rathod, \\ E-mail: rathodpratik56@gmail.com
}

Copyright: (c) the author(s), publisher and licensee Medip Academy. This is an open-access article distributed under the terms of the Creative Commons Attribution Non-Commercial License, which permits unrestricted non-commercial use, distribution, and reproduction in any medium, provided the original work is properly cited.

\begin{abstract}
Background: The clinical and functional outcome of total knee arthroplasty was studied using low cost Indian knee prosthesis called Destiknee by Maxx Company in government medical hospital. The objectives was to do assessment of pain relief, joint mobility and deformity correction post-operatively, pre-operative and post-operative Knee society score comparison.

Methods: Patients included were those who underwent primary total knee arthroplasty in Department of Orthopaedics, GMCH Aurangabad from January 2020 to January 2021. Clinical and functional assessment was done using the Knee society score and x-rays at 3, 6 and 12 months intervals.

Results: At 1 year follow up of 28 knees, there was an improvement in the average pre-op Knee society score of 53.92 to average post-op score of 86.25 and in the range of motion from 80.42 degree to 127.32 degrees and knee flexion deformity improved from 15.25 degrees to 2.17 degrees, all of which had a $\mathrm{p}$ value $<0.05$ are significant statistically. One diabetic patient with poor glycemic control had superficial infection and one developed minor pulmonary embolism which recovered with medical management. Patients had good satisfaction both in unilateral and bilateral TKA.

Conclusions: TKA resulted in significant reduction in knee pain and improvement in the functional ability of patients. The results of this low cost Indian prosthesis in a government rural setup with no laminar airflow with good efficacy and minimal complications are excellent. It was a boon for the rural population suffering from knee pain.
\end{abstract}

Keywords: Clinical and functional outcome, Knee society score, Low cost Indian knee prosthesis, Total knee arthroplasty

\section{INTRODUCTION}

Total knee arthroplasty (TKA) includes replacing a damaged knee joint by an artificial joint comprising of femoral and tibial component with an articular insert(liner). Severe knee pain is most commonly caused due to osteoarthritis, rheumatoid arthritis and posttraumatic arthritis out of which the most common being osteoarthritis of the knee causing severe pain and affecting the functional ability. The overall prevalence of osteoarthritis of knee was $28.7 \%$ and the risk factors include female gender, old age, obesity and sedentary work. ${ }^{1,2}$ Not many patients undergo TKA in rural government setup as compared to the urban population. Hence, most of the patients in rural setup were subjected to medical treatment, behavioral change, weight reduction and exercise as management of severe knee pain due to arthritis. ${ }^{3}$ With the development of low cost Indian TKA implants, better facilities and increasing awareness among rural population, TKA has emerged as a potential treatment option for severe arthritis. As a tertiary care center caters to a large low-middle class families, there 
was a need for a low cost TKA prosthesis in improving the quality of life of people who did not have a good outcome with non surgical methods. ${ }^{4}$ Certain downsides of TKA includes- thromboembolism, patellofemoral complications, periprosthetic fractures, neurovascular complications, instability, malalignment, stiffness, osteolysis and infection of the knee which may require reoperation. ${ }^{5}$ In this study we are trying to assess the short term outcome of low cost Indian TKA prosthesis in relieving knee pain and improving the functional ability of the patient in tertiary rural government medical hospital with limited infrastructure. ${ }^{6}$ As these patients are very poor and their daily activities are severely affected by severe knee pain we tried to offer a low cost Indian made total knee arthroplasty prosthesis which was affordable for the poor and gave good results with minimal complications. This study was not done to promote any Brand or company and was not sponsored by any TKA company.

\section{METHODS}

This was a prospective study conducted under the guidelines of ethical committee of the institution in Government medical college and hospital, Aurangabad from January 2020 to January 2021.

\section{Inclusion criteria}

Patients with primary osteoarthritis of the knee, with rheumatoid arthritis of the knee, and with post traumatic arthritis of the knee were imcluded in the study.

All patients admitted in Government medical college, Aurangabad treated with low cost TKA between January 2020-2021 underwent evaluation for 12 months postTKA. Severe knee pain affecting lifestyle was the main indication for surgery. The Knee Society score was used to evaluate pain, function and quality of life. The assessment and confirmation of the clinical findings of any deformities was done by pre-operative $\mathrm{x}$-rays. The Knee society score was used to clinically and functionally evaluate patients. ${ }^{8-}$ ${ }^{10}$ This score is divided into 2 parts. Part 1 is Knee score which includes pain, total range of flexion, flexion contracture (if present), extension lag, alignment, stabilityanteroposterior and mediolateral. Part 2 is function score which includes, walking, stairs, walking aids used.

The scoring is as follows-

$$
\begin{aligned}
& \text { - } 80-100: \text { Excellent } \\
& \text { - 70-79: Good } \\
& \text { - 60-69: Fair } \\
& \text { - } \quad 60: \text { Poor }
\end{aligned}
$$

Patients were evaluated with Knee society score, Range of motion (ROM) and flexion deformity which were analyzed pre-operatively and post-operatively. Femoral component used was posterior stabilized type (both cruciates removed). Tibial component was mobile bearing type. And fixation between the components was cemented.
All the implants used were low cost Indian model called Destiknee by Maxx company.

\section{Surgical procedure}

Patient was asked to take bath a night prior and cleaning of the surgical site was done with betadine and covered with sterile pad and bandaged overnight. Intravenous antibiotic (Third generation cephalosporin) was administered once the night before (12 hours prior to surgery) and the second dose 30 minutes before surgery. Urinary catheterization was done. Position was supine with hip and knee in 45 degree flexion. Anaesthesia used was spinal with or without epidural. Tourniquet was applied. Medial parapatellar 8-10 inches incision was used with knee in 30o flexion. Skin flaps elevated, soft tissues dissected. Patella was then everted. Anterior cruciate ligament was released and medial and lateral meniscus were removed to gain access to the femoral canal for utilization of distal femoral cutting guide and jig with an intramedullary (IM) drill was used.

The angle set on the guide is patient specific based on preoperative evaluation (AP xray), generally giving 6o valgus and additional 40 and 80 valgus cuts are also available. Approximately 9-10 mm of distal femur is cut followed by anterior, posterior and chamfer cut with the 5-in-1 cutting block. Box cuts are then taken in posterior stabilized implant. To cut the proximal tibia, tibia cutting guide is used with the goal of cutting the bone perpendicular to the tibial axis and it is stabilized spring around the ankle. The rotation is set according to the reference of medial one third of tibial tubercle (proximally) and a point slightly medial to the center of ankle joint (distally). Another reference taken is second ray of foot and the tibial crest. Alignment is confirmed using the tibial alignment block and tibial alignment rod. Trial components are tested and confirmed. The definitive inserts are placed with cement and spacer in between. Tourniquet is now deflated. The wound is closed after placing drain no 14. Patient is closely monitored in intensive care unit (ICU) for a day. Patient's hemogram is tested and a point of packed cell volume administered if less than 10 gram $\%$. Urinary catheter is removed 12 hours after surgery and injection enoxaparin administered subcutaneously for 3 days- the first dose starting 12 hours after surgery for prophylaxis of deep vein thrombosis (DVT).

Drain removal is done after $12-24$ hours. Starting postoperative day-0 IV antibiotics is given for 3 days followed by oral antibiotics for further 5 days. On day- 1 bedside sitting is started, on day -2 knee range of motion exercises and supported ambulation gradually shifting to unsupported ambulation as tolerated by the patient, on day-4 staircase climbing was started and patient discharged on day-5 (For unilateral cases). For bilateral TKA cases, the patient was stabilized and mobilized adequately after the first procedure and the surgery on the other leg was done after 10-14 days (due to government setup restraints and financial stresses on the patient) 


\section{Ethical approval}

Ethical approval for conducting the study was taken from the Ethical Committee of the local institution.

\section{Statistical analysis}

The data of patients who fulfilled the inclusion criteria were tabulated in electronic spreadsheet (Microsoft Excel 2010) and data was analyzed using SPSS 24.0 p-value of $<0.05$ was considered statistically significant.

\section{RESULTS}

In our study, we found that majority of the study population belonged to the age group 66-70 years (40\%) followed by $71-75$ years $(26.66 \%)$ and the mean age was 66.10 years. Females $(53.33 \%)$ were found to be more as compared to males $(46.66 \%)$. Right side $(46.66 \%)$ was more commonly involved than left $(33.33 \%)$ and only $20 \%$ patients had bilateral involvement (Table 1).

Table 1: Age, gender and side distribution.

\begin{tabular}{|ll|}
\hline Parameter & Value \\
\hline Age & \\
\hline Mean \pm SD & $66.10 \pm 6.24$ \\
\hline Range & $52-75$ \\
\hline Gender & \\
\hline Male & $46.66 \%$ \\
\hline Female & $53.33 \%$ \\
\hline Side affected & \\
\hline Right & $46.66 \%$ \\
\hline Left & $33.33 \%$ \\
\hline Bilateral & $20 \%$ \\
\hline
\end{tabular}

Table 2: Various scoring systems used in the study to evaluate the patients.

\begin{tabular}{|llll|}
\hline Variable & $\begin{array}{l}\text { Pre- } \\
\text { operative } \\
\text { Mean } \pm \text { SD }\end{array}$ & $\begin{array}{l}\text { Post- } \\
\text { operative } \\
\text { Mean } \pm \text { SD }\end{array}$ & P value \\
\hline $\begin{array}{l}\text { Knee Society } \\
\text { score } \\
\text { (out of 100) }\end{array}$ & $53.92 \pm 8.23$ & $86.25 \pm 6.31$ & $<0.05$ \\
\hline $\begin{array}{l}\text { Range of } \\
\text { motion } \\
\text { (in degrees) }\end{array}$ & $80.42 \pm 19.36$ & $127.32 \pm 14.31$ & $<0.05$ \\
\hline $\begin{array}{l}\text { Flexion } \\
\text { deformity } \\
\text { (in degrees) }\end{array}$ & $15.25 \pm 6.78$ & $2.17 \pm 1.38$ & $<0.05$ \\
\hline
\end{tabular}

The Knee society score (out of 100) (Table 2) improved from pre-operative $53.92 \pm 8.23$ (range 40-68) to postoperative $86.25 \pm 6.31$ (range $75-96$ ), the range of motion which was pre-operatively $80.42 \pm 19.36$ (range 48-120) improved to post-operative $127.32 \pm 14.31$ (range 102-150) and the flexion deformity improved from pre-operative
$15.25 \pm 6.78$ (range 2-28) to post-operative $2.17 \pm 1.38$ (range 1-6).

Table 3: Post-operative complications.

\begin{tabular}{|lll|}
\hline Complications & No. of cases & Percentage \\
\hline None & 26 & 92.85 \\
\hline Infection & 1 & 5 \\
\hline Pulmonary embolism & 1 & 5 \\
\hline
\end{tabular}

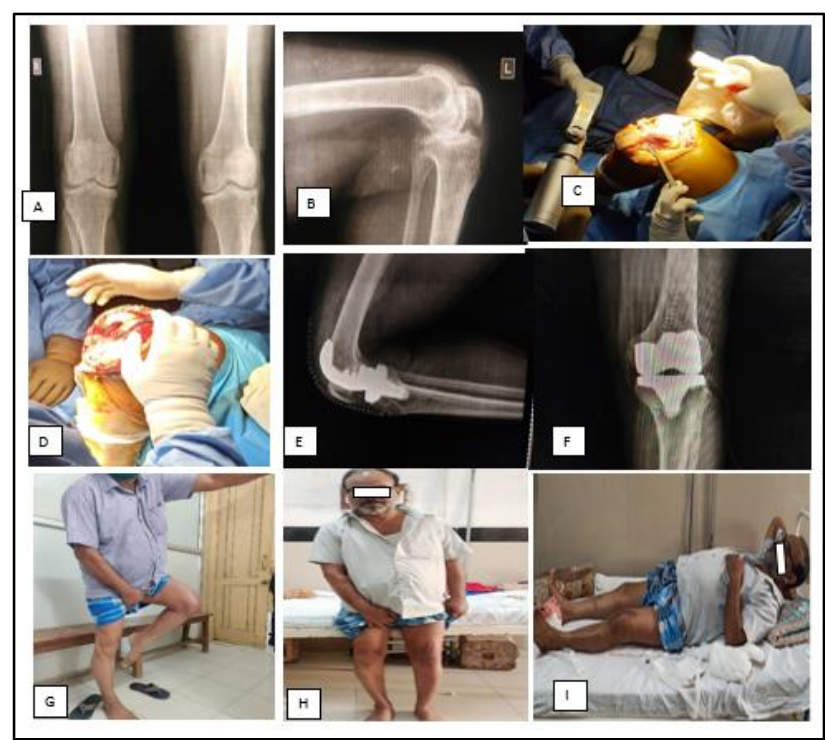

Figure 1: Patient with bilateral osteoarthritis on radiographs showing good post-operative function after TKA.

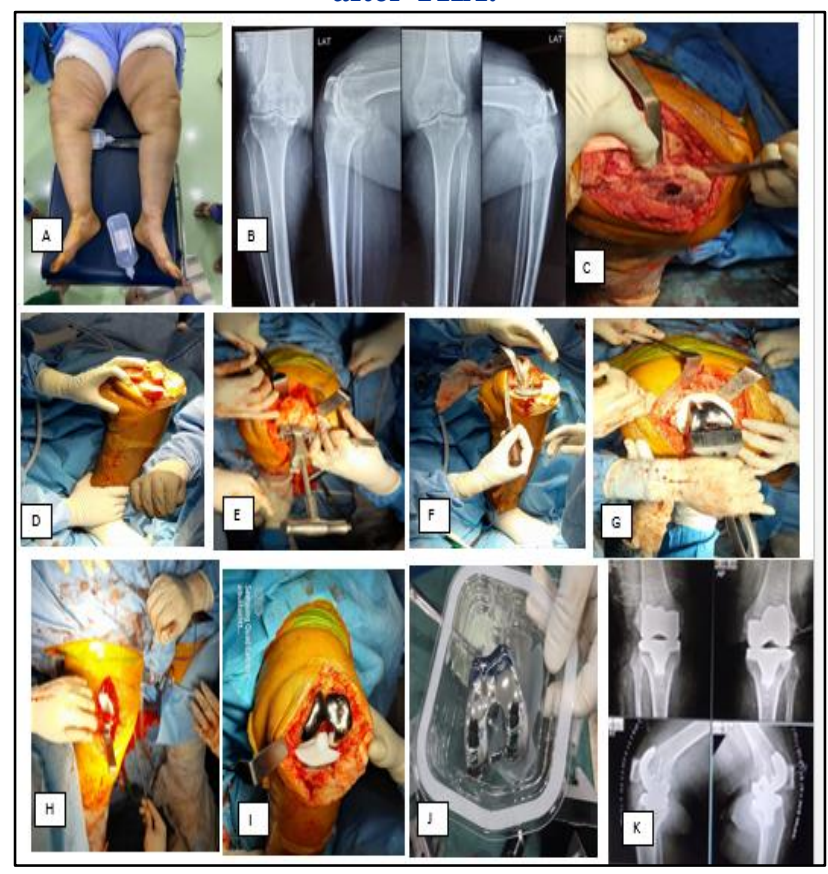

Figure 2: The patient had bilateral osteoarthritis as seen clinically and radiographically for which the patient underwent TKA as shown in the postoperative radiograph. 


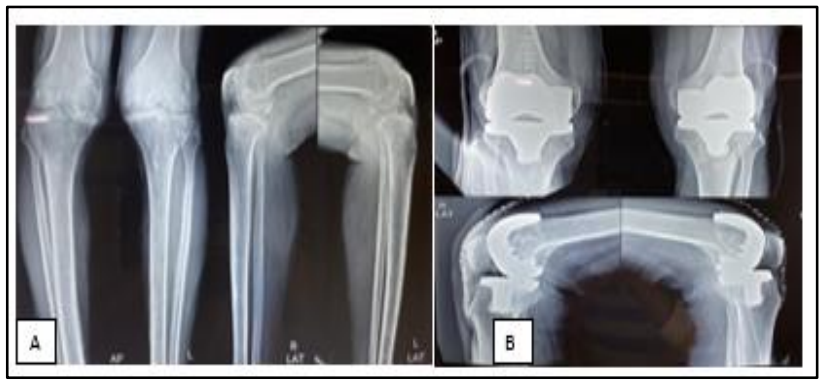

Figure 3: Another case with bilateral osteoarthritis of knee who underwent bilateral TKA.

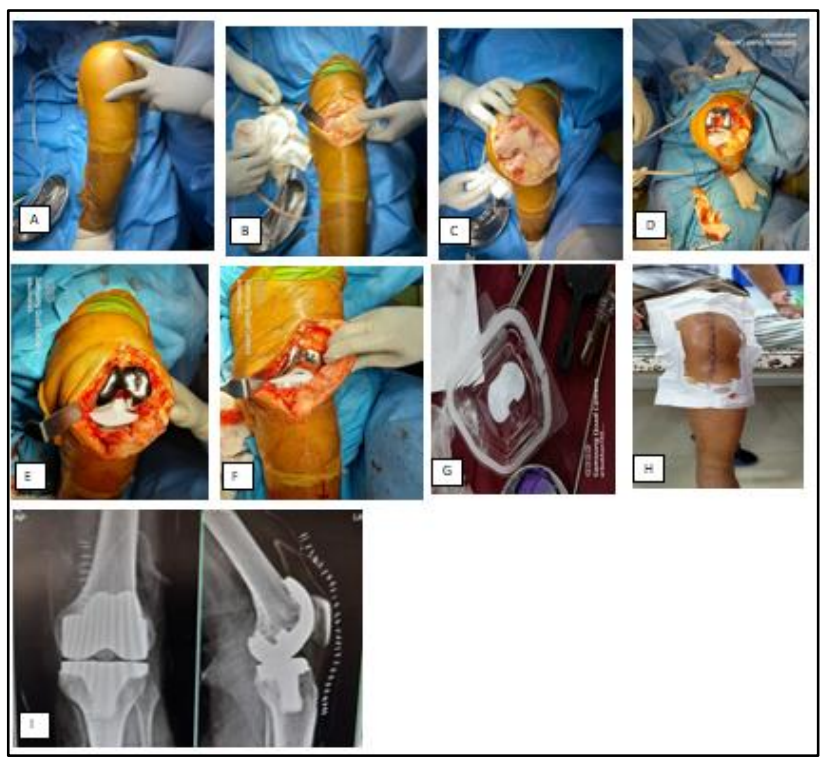

Figure 4: The intra-operative steps of the procedure and the "destiknee" model as seen in the images and radiographs.

Out of the 28 operated knees, $26(92.85 \%)$ had no complications. One patient $(5 \%)$ who was diabetic with poor compliance to oral hypoglycemic drugs had superficial infection but the patient was lost to follow up during covid pandemic. 1 patient $(5 \%)$ showed signs of minor pulmonary embolism on chest x-ray, CT pulmonary angiography and required ICU admission for 4 days and the patient recovered completely with the help of cardiologist who initiated oxygen therapy, low molecular weight heparin and was shifted to general ward on 5th day. A revision surgery was required in none of the patients (Table 3).

\section{DISCUSSION}

A significant amount of morbidity accounts due to arthritis of knee especially osteoarthritis. This hampers the activities of daily living and total knee arthroplasty is on the rise in absence of any medical treatment to stop its progression. Inspite of this, TKA has not been accepted by rural people as a mode of treatment who continue to take medical management due to financial burden. Unlike total hip replacements, wear and tear of implant does not necessitate change of implants in total knee replacements. Early surgery has shown better post-operative relief and satisfaction in these patients. ${ }^{7,11}$

For all the patients with bilateral affection in our study, we did a staged bilateral knee replacement as most of our patients belonged to lower middle class. ${ }^{12,13}$ All the patients who underwent bilateral knee replacement were satisfied after both operations and had excellent function. Today, with technological advancements we have new TKA designs (high flexion knee, medial pivot knee), newer surgical approaches (minimally invasive, navigation systems) and newer arthroplasty materials (newer polyethylene, oxinium and uncemented knee replacements). ${ }^{16}$

In our study, the mean Knee society score (KSS) was found to improve from 53.92 pre-operatively to 86.25 post-operatively. Jacobs et al found KSS to improve from 28 pre-operatively to 88 post-operatively. ${ }^{10}$ Mathijssen et al found KSS to improve from 50 pre-operatively to 90 post-operatively. ${ }^{18}$ Sancheti et al found KSS to improve from 39.4 pre-operatively to 87.5 post-operatively. ${ }^{19}$ Levitsky et al found KSS to improve from 23.2 preoperatively to 89.9 post-operatively. ${ }^{20}$ Aglietti et al found KSS to improve from 22.5 pre-operatively to 90 postoperatively. ${ }^{25}$

In our study, the mean Range of motion (ROM) improved from $80.42^{0}$ pre-operatively to $127.32^{\circ}$ post-operatively. In a study by Jacobs et al ROM improved from $80.42^{\circ}$ preoperatively to $127.32^{0}$ post-operatively.10 In a study by Mathijssen et al ROM improved from $111^{\circ}$ pre-operatively to $123^{0}$ post-operatively. ${ }^{18}$ In a study by Sancheti et al ROM improved from $106.2^{0}$ pre-operatively to $132.1^{0}$ post-operatively. ${ }^{19}$ In a study by Martins et al ROM improved from $28^{0}$ pre-operatively to $88^{\circ}$ postoperatively. $^{23}$ In a study by Bellemans et al ROM improved from $71^{\circ}$ pre-operatively to $93^{0}$ postoperatively. ${ }^{24}$ In our study, the mean Flexion deformity improved from $15.25^{\circ}$ pre-operatively to $2.17^{0}$ postoperatively. In a study by Sancheti et al the flexion deformity improved from $10.7^{0}$ pre-operatively to $3.19^{0}$ post-operatively. ${ }^{19}$

The complications found to happen in our study were superficial infection in 1 patient $(5 \%)$ and Pulmonary embolism in 1 patient (5\%). Mathijssen et al found infection in $0.7 \%$ cases, wound leakage in $1.4 \%$ cases and severe disability in $0.7 \%$ cases of their study. ${ }^{18}$ Bellemans found severe polyethylene wear in 1 patient in their study. ${ }^{24}$ Aglietti et al found deep infection in 2 cases and painful impingement of patella in 3 cases $(7 \%)$ in their study. ${ }^{25}$ Miyasaka et al found sepsis in 2 cases, aseptic loosening in 3 cases and traumatic patella fracture in 1 case in their study. ${ }^{26}$ Financial burden continues to be a major obstacle preventing rural population from undergoing TKA in osteoarthritis of knee. The Indian made Destiknee model by Maxx Company is a low cost alternative with 
excellent pain relief and functional results for such patients.

Large number of needy poor rural population with financial constraints having knee pain visit tertiary government setup. At government hospital, adequate surgical expertise is available, only implant has to be outsourced. Even this outsourced implant which the patient has to buy is a huge financial burden for these patients belonging to poor, farmer families. These patients who have incapacitating knee pain often develop other comorbidities and compromise their lifestyle.

To help these patients we need to have an implant developed in India for Indian markets. Taking inspiration from our Honorable PM flagship Aatmanirbhar and Make in India programs, we intend to publish short term and long term results of Indian prosthesis. There is a saving of 1015 thousand rupees which is a significant amount of savings for these poor patients. Hence, this study was conducted to evaluate the functional outcomes of this Indian Total knee arthroplasty prosthesis. This study was not done to promote any brand or company and was solely done to evaluate the efficacy of low cost TKA models for the poor rural population.

\section{CONCLUSION}

Knee pain is significantly reduced and functional ability is greatly improved after total knee arthroplasty but the imported implant is not affordable for the rural population. Therefore, the low cost Indian model Destiknee by Maxx is a great option with good efficacy and minimal complications for the rural population suffering from knee pain coming to tertiary government medical hospital. This study was a short term study conducted during the covid pandemic period and needs further long term study and evaluation.

\section{Funding: No funding sources}

Conflict of interest: None declared

Ethical approval: The study was approved by the institutional ethics committee

\section{REFERENCES}

1. Silverwood V, Blagojevic-Bucknall $\mathrm{M}$, Jinks C, Jordan JL, Protheroe J, Jordan KP. Current evidence on risk factors for knee osteoarthritis in older adults: a systematic review and meta-analysis. Osteoarthritis and Cartilage. 2015;23(4):507-15.

2. Pal CP, Singh P, Chaturvedi S, Pruthi KK, Vij A. Epidemiology of knee osteoarthritis in India and related factors. Indian J Orthop. 2016;50(5):518-22.

3. Mitchell HL, Hurley MV. Management of chronic knee pain: A survey of patient preferences and treatment received. BMC Musculoskelet Disord. 2008;9:123.

4. Drewett RF, Minns RJ, Sibly TF. Measuring outcome of total knee replacement using quality of life indices. Ann R Coll Surg Engl. 1992;74(4):28690.

5. Healy WL, Della Valle CJ, Lorio R. Complications of total knee arthroplasty: standardized list and definitions of the knee society. Clin Orthop Relat Res. 2013;471:215-20.

6. David F, Rafael C, Francisco F, Carolina A, Alan G, Jaime C. Clinical and functional outcomes of primary total knee arthroplasty: a South American perspective. Arthroplasty Today. 2019;5(3):368-71.

7. Fortin PR, Clarke AE, Joseph L, Liang MH, Tanzer M, Ferland D, et al. Outcomes of total hip and knee replacement: preoperative functional status predicts outcomes at six months after surgery. Arthritis Rheum. 1999;42:1722-8.

8. Scuderi GR, Bourne RB, Noble PC, Benjamin JB, Lonner JH, Scott WN. The new knee society knee scoring system. Clin Orthop Relat Res. 2012;470(1):3-19.

9. Insall JN, Dorr LD, Scott RD, Scott WN. Rationale of the knee society clinical rating system. Clin Orthop Relat Res. 1989;(248):13-4.

10. Jacobs CA, Christensen CP. Correlations between knee society function scores and functional force measures. Clin Orthop Relat Res. 2009;467(9):24149.

11. Fortin PR, Penrod JR, Clarke AE, St-Pierre Y, Joseph $\mathrm{L}$, Bélisle $\mathrm{P}$, et al Timing of total joint replacement affects clinical outcomes among patients with osteoarthritis of the hip or knee. Arthritis Rheumatism. 2002;46: 3327-30.

12. Stefánsdóttir A, Lidgren L, Robertsson O. Higher early mortality with simultaneous rather than staged bilateral tkas: results from the swedish knee Arthroplasty Register. Clin Orthop Relat Res. 2008;466:3066-70.

13. Hutchinson JRM, Parish EN, Cross MJ. A comparison of bilateral uncemented total knee arthroplasty-simultaneous or staged? J Bone Joint Surg. 2006;88B(1):40-3.

14. Mihalko WM. Arthroplasty of the knee. In: Azhar FM, Beaty JH, Canale ST (Eds). Campbell's Operative Orthopaedics. Thirteenth edition. Philadelphia. Elsevier. 2017:396-534.

15. Dowsey MM, Choong PFM. The utility of outcome measures in total knee replacement surgery. Int $\mathbf{J}$ Rheumatol. 2013;8:98-102.

16. Wong JM, Khan WS, Chimutengwende-Gordon M,Dowd, GSE. Recent advances in designs, approaches and materials in total knee replacement: literature review and evidence today. Journal of Perioperative Practice. 2011;21(5):165-71.

17. Losina E, Walensky RP, Reichmann WM, et al. Impact of obesity and knee osteoarthritis on morbidity and mortality in older Americans. Ann Intern Med. 2011;154(4):217-26.

18. Mathijssen NMC, Verburg H, London NJ, Landsiedl M, Dominkus M. Patient reported outcomes and implant survivorship after Total knee arthroplasty with the persona knee implant system: two year 
follow up. BMC Musculoskelet Disord. 2019;20(1):97.

19. Sancheti KH, Laud NS, Bhende H, Reddy G. The INDUS knee prosthesis prospective multicentric trial of a posteriorly stabilized high-flex design: 2 years follow-up. Indian J Orthop. 2009;43(4):367-74.

20. Levitsky KA, Harris WJ, McManus J, Scott RD. Total knee arthroplasty without patellar resurfacing. Clinical outcomes and long-term follow-up evaluation. Clin Orthop Relat Res. 1993;(286):11621.

21. Shaw JA. Hybrid fixation modular tibial prosthesis. Early clinical and radiographic results and retrieval analysis. J Arthroplasty. 1995;10(4):438-47.

22. Rand JA. Modularity in total knee arthroplasty. Acta Orthop Belg. 1996;62(1):180-6.

23. Martin SD, McManus JL, Scott RD, Thornhill TS. Press-fit condylar total knee arthroplasty. 5- to 9-year follow-up evaluation. J Arthroplasty. 1997;12(6):603-14.
24. Bellemans J, Victor J, Westhovens R, Dequeker J, Fabry G. Total knee arthroplasty in the young rheumatoid patient. Acta Orthop Belg. 1997;63(3):189-93.

25. Aglietti P, Buzzi R, Segoni F, Zaccherotti G. InsallBurstein posterior-stabilized knee prosthesis in rheumatoid arthritis. J Arthroplasty. 1995;10(2):21725.

26. Miyasaka KC, Ranawat CS, Mullaji A. 10- to 20-year followup of total knee arthroplasty for valgus deformities. Clin Orthop Relat Res. 1997;(345):2937.

Cite this article as: Aziz AMA, Rathod P, Patel A. Clinical evaluation of low cost Indian knee prosthesis in government medical colleges. Int J Res Orthop 2021;7:583-8. 